\title{
Adsorption of Co(II) and Mn(II) Ions on Mesoporous Silica SBA15 Functionalized with Amine Groups
}

\author{
Seongmin Kim, Seungsoo Park, Yosep Han, Joonchul Choi and Jaikoo Park* \\ Department of Natural Resources and Environmental Engineering, Hanyang University, \\ 222 Wangsimni-ro, Seongdong-gu, Seoul 133-791, Republic of Korea
}

\begin{abstract}
The adsorption characteristics of Co(II) and Mn(II) ions on mesoporous silica SBA15 were investigated. SBA15 was synthesized from the silicate precursor tetraethyl-orthosilicate (TEOS), and it was functionalized with ethylene-diamine-tetra-acetic-acid (EDTA) and N,N-dimethylacetamide (DMAC), which consists of the amine functional groups. It was also characterized by nitrogen adsorption-desorption analysis, element analysis (EA), Fourier transform infrared spectroscopy (FT-IR), scanning electron microscopy (SEM), and transmission electron microscopy (TEM). The adsorption capacities of EDTA functionalized SBA15 for Co(II) and DMAC functionalized SBA15 for Mn(II) in a single component system were found to be $10.12 \mathrm{mg} / \mathrm{g}$ and $6.8 \mathrm{mg} / \mathrm{g}$, respectively. These values are about 10 times higher than that of assynthesized SBA15. The adsorption isotherms and kinetics data were found to follow the Langmuir adsorption isotherm model and the Pseudosecond order kinetic model $\left(r^{2}>0.99\right)$. After the 5 adsorption cycles, over $90 \%$ regeneration efficiency was achieved for the functionalized SBA15, which would be applied for recovery of the metals. [doi:10.2320/matertrans.M2014128]
\end{abstract}

(Received April 10, 2014; Accepted June 20, 2014; Published August 8, 2014)

Keywords: adsorption, functionalization, cobalt, manganese, mesoporous silica

\section{Introduction}

Rare metals, such as cobalt, manganese, lithium, and nickel are widely used in energy and electronics industries. In recent years, the usage of lithium ion batteries that contain high amounts of rare metals such as cobalt and manganese has increased remarkably, resulting in the generation of enormous amounts of waste lithium ion batteries. To prevent environmental pollution and recover rare metals, recycling technology of lithium ion batteries is a focus of current research. ${ }^{1-8)}$

A wide variety of recycling techniques to recover metals such as cobalt and manganese from spent lithium ion batteries are available such as liquid-liquid extraction, ion exchange, membrane filtration, precipitation, oxidation/ reduction, coagulation and adsorption..$^{9-12)}$ Among them, adsorption is becoming increasingly used in many recycling processes due to its simplicity, low cost, easy operation, and selectivity. ${ }^{9,12,13)}$ Adsorbents (e.g. mesoporous silica) have been developed to improve the effectiveness at very low metal concentration and regeneration efficiencies. ${ }^{14-16)}$

Mesoporous materials, having unique large surface area, well-defined pore size and pore shape, have been extensively studied for its widespread applications in fields of adsorption, catalysis, sensing and separation. Moreover in comparision with other mesoporous silica, SBA15 exhibits thick pore walls which provide significantly improved hydrothermal stability, being suitable for use in aqueous solutions. ${ }^{9,17-21)}$

Recently, functionalized mesoporous materials are receiving attention due to their strong binding affinity for metal ion. Functional group addition may increase the adsorption capacity, make adsorbent more selective, or increase the stability of the adsorbent. ${ }^{9,11,12,18,19,22-25)}$ In the case of mesoporous silicas functionalized with chelating agents, the main applications are adsorption of the metal ions from aqueous solutions, separation of the different metals,

*Corresponding author, E-mail: jkpark@hanyang.ac.kr or preconcentration of the metal ions prior to their analysis. . $^{12,14,19,23-26)}$

In this paper, functionalized mesoporous silica SBA15 was prepared as metal ion adsorbents. The adsorbents were characterized for physical properties and tested for the adsorption of metal ions in aqueous solution. After adsorption of the metal ions, the regeneration of the functionalized adsorbents was also studied.

\section{Experiments}

\subsection{Preparation of the mesoporous silica}

Mesoporous silica SBA15 was prepared by the synthesis procedure by Zhao. ${ }^{20)}$ In a typical synthesis, $4 \mathrm{~g}$ of triblock copolymer Poly(ethylene glycol)-block-poly(propylene glycol)-block-poly(ethylene glycol) (P123) was dissolved in $120 \mathrm{~g}$ of $2 \mathrm{M}$ hydrochloric acid $(\mathrm{HCl})$ aqueous solution and $30 \mathrm{~g}$ of distilled water. The mixture was stirred at $35^{\circ} \mathrm{C}$. Tetraethyl-orthosilicate (TEOS) was added to this solution, and the synthesis was carried out by stirring at $35^{\circ} \mathrm{C}$ for $20 \mathrm{~h}$, and aged at $90^{\circ} \mathrm{C}$ for $24 \mathrm{~h}$. The precipitated products were then filtered, washed thoroughly with distilled water, dried at $60^{\circ} \mathrm{C}$ for $24 \mathrm{~h}$, and finally calcined at $550^{\circ} \mathrm{C}$ for $4 \mathrm{~h}$. The textural properties of the samples were determined through nitrogen physisorption by using a surface area and porosity analyzer (ASAP 2020, Micromeritics, USA). From the isotherm curve, we measured the pore size distribution using the Barrett-Joyner-Halenda (BJH) model and calculated the specific surface area using the Brunauer-Emmett-Teller (BET) model. The pore structures and surface forms of the samples were observed using SEM (Nova NanoSEM 450, FEI, USA) and TEM (JEM2001F, JEOL, Japan).

\subsection{Functionalization of the mesoporous silica}

To graft the silica surface, $1.1 \mathrm{~g}$ of mesorporous materials were dispersed in toluene and $4.1 \mathrm{mmol}$ of EDTA or DMAC were added. The mixture was refluxed for $24 \mathrm{~h}$. The precipitated products were then filtered washed thoroughly 
with ethanol, stirred with ethanol at room temperature for $24 \mathrm{~h}$, and finally dried at $60^{\circ} \mathrm{C}$ for $24 \mathrm{~h}$. The as-synthesized SBA15 is referred to as MS, the EDTA functionalized SBA15 is referred to as MS1 and the DMAC functionalized SBA15 is referred to as MS2. The surface properties of the samples were measured using FT-IR spectrometer (FT-IR 4100, JASCO, Japan) and element analyzer (Thermo Flash EA1112, Thermo Fisher Scientific, USA).

\subsection{Adsorption studies}

The single-component adsorption capacity of metal ions was measured by adding $0.1 \mathrm{~g}$ of adsorbent into $100 \mathrm{ml}$ of aqueous solution containing $\mathrm{Co}$ (II) and $\mathrm{Mn}$ (II) with concentrations of $100 \mathrm{ppm}$. Co(II) and $\mathrm{Mn}(\mathrm{II})$ solutions were prepared by dissolving appropriate amounts of $\mathrm{Co}$ (II) and $\mathrm{Mn}(\mathrm{II})$ nitrate salts in deionized water. The $\mathrm{pH}$ of the aqueous solutions was adjusted to 2.0 by adding the appropriate amount of $\mathrm{HCl}$ and sodium hydroxide $(\mathrm{NaOH})$ solution. The adsorption experiments were conducted in a shaker incubator kept at room temperature $\left(25^{\circ} \mathrm{C}\right)$. After the adsorption test, the metal concentration in the aqueous solution was measured by an inductively coupled plasma mass spectrometer (ICPMS) (Ultima2C, Horiba, Japan).

The adsorption capacity $\left(Q_{\mathrm{e}}\right)$ of the adsorbent for the metal ion is the solution of the following equation: $:^{3,11,14,27)}$

$$
Q_{\mathrm{e}}=\frac{\left(C_{\mathrm{i}}-C_{\mathrm{e}}\right)}{M} V
$$

where, $Q_{\mathrm{e}}(\mathrm{mg} / \mathrm{g})$ is the amount of solute adsorbed per unit mass adsorbent, $C_{\mathrm{i}}(\mathrm{mg} / \mathrm{L})$ and the $C_{\mathrm{e}}(\mathrm{mg} / \mathrm{L})$ are the initial and equilibrium concentration of solute in solution, $M(\mathrm{~g})$ is the weight of the adsorbent, and $V(\mathrm{~L})$ is the volume of the aqueous solution.

To study the effects of $\mathrm{H}^{+}$concentrations on metal adsorption, the solution of $\mathrm{pH}$ was varied from 1 to 5 .

The adsorption kinetics of the metal ions were measured by adding $0.1 \mathrm{~g}$ of adsorbent into $100 \mathrm{ml}$ of aqueous solution containing $\mathrm{Co}$ (II) and $\mathrm{Mn}$ (II) with concentrations of 100 ppm. The mixtures were shaken for $10-1440 \mathrm{~min}$. The Pseudo-second-order kinetics were used to evaluate the adsorption kinetics and the rate constants. The non-linear mathematical expression of the Pseudo-second-order kinetics is the solution of the following equation: ${ }^{11,14,26-28)}$

$$
Q_{\mathrm{t}}=\frac{Q_{\mathrm{e}}^{2} K_{\mathrm{t}} t}{1+Q_{\mathrm{e}} K_{\mathrm{t}} t}
$$

where, $t(\mathrm{~min})$ is the reaction time, $Q_{\mathrm{t}}(\mathrm{mg} / \mathrm{g})$ is the adsorption capacity at time $\mathrm{t}$, and $K_{\mathrm{t}}(\mathrm{g} / \mathrm{mg} \mathrm{min})$ is the rate constant of the adsorption. To obtain the model parameters, the linearized Pseudo-second-order equation is given by:

$$
\frac{t}{Q_{\mathrm{t}}}=\frac{1}{K_{\mathrm{t}} Q_{\mathrm{e}}^{2}}+\frac{t}{Q_{\mathrm{e}}}
$$

The adsorption isotherms of the metal ions were measured by adding $0.1 \mathrm{~g}$ of adsorbent into $100 \mathrm{ml}$ of aqueous solution containing $\mathrm{Co}(\mathrm{II})$ and $\mathrm{Mn}$ (II) with concentrations of 10 $200 \mathrm{ppm}$. The Langmuir isotherm equation was used to evaluate the adsorption isotherm. The non-linear mathematical expression of the Langmuir isotherm equation is the solution of the following equation: ${ }^{11,14,26-28)}$

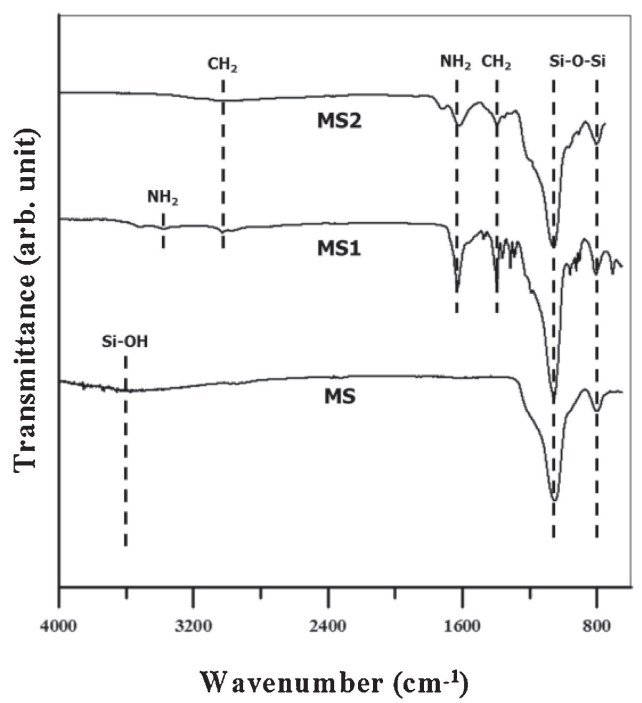

Fig. 1 FTIR spectra of MS and amine functionalized mesoporous silicas MS1 and MS2, respectively.

$$
Q_{\mathrm{e}}=\frac{Q_{\max } K_{\mathrm{L}} C_{\mathrm{e}}}{1+K_{\mathrm{L}} C_{\mathrm{e}}}
$$

where, $Q_{\max }$ and $K_{\mathrm{L}}$ are the characteristics of the Langmuir parameter. $Q_{\max }(\mathrm{mg} / \mathrm{g})$ is the monolayer adsorption capacity, and $K_{\mathrm{L}}(\mathrm{L} / \mathrm{mg})$ is the constant related to the intensity of adsorption. To obtain the model parameters, the linearized Langmuir equation is given by:

$$
\frac{C_{\mathrm{e}}}{Q_{\mathrm{e}}}=\frac{1}{Q_{\max } K_{\mathrm{L}}}+\frac{C_{\mathrm{e}}}{Q_{\max }}
$$

The binary-component adsorption capacity of the metal ions were measured by adding $0.1 \mathrm{~g}$ of adsorbent into $100 \mathrm{ml}$ of aqueous solution containing $\mathrm{Co}$ (II) and $\mathrm{Mn}$ (II) with concentrations of $100 \mathrm{ppm}$.

Regeneration of the spent adsorbents was performed in acidic conditions. After the adsorption experiments, the spent adsorbent was separated from the aqueous solution by filtering and centrifuge. Then, desorption of the adsorbents was carried out using $2 \mathrm{M}$ nitric acid $\left(\mathrm{HNO}_{3}\right)$ solution at $25^{\circ} \mathrm{C}$, $200 \mathrm{rpm}$ and $24 \mathrm{~h}$. This procedure was repeated five times, and the adsorption capacity after each cycle was measured. The regeneration efficiency is the following equation: ${ }^{11,14-16)}$

$$
\text { Regeneration efficiency }(\%)=\frac{Q_{\mathrm{r}}}{Q_{0}} \times 100
$$

where, $Q_{0}$ and $Q_{\mathrm{r}}$ are the adsorption capacity $(\mathrm{mg} / \mathrm{g})$ of the adsorbents before and after the regeneration experiments, respectively.

\section{Results and Discussion}

\subsection{Materials characterization}

Figure 1 The FT-IR spectra of the as-synthesized SBA15 MS, functionalized SBA15 MS1 and MS2 are shown in Fig. 1. The peaks between 800 and $1050 \mathrm{~cm}^{-1}$, observed in the sample represent the $\mathrm{Si}-\mathrm{O}-\mathrm{Si}$ vibration, which is common in silica materials. The broad peak appearing between 3200 and $3600 \mathrm{~cm}^{-1}$ was assigned to the stretching vibrations of the $\mathrm{Si}-\mathrm{OH}$ groups in $\mathrm{MS}^{21,29)}$ After the functionalization, 

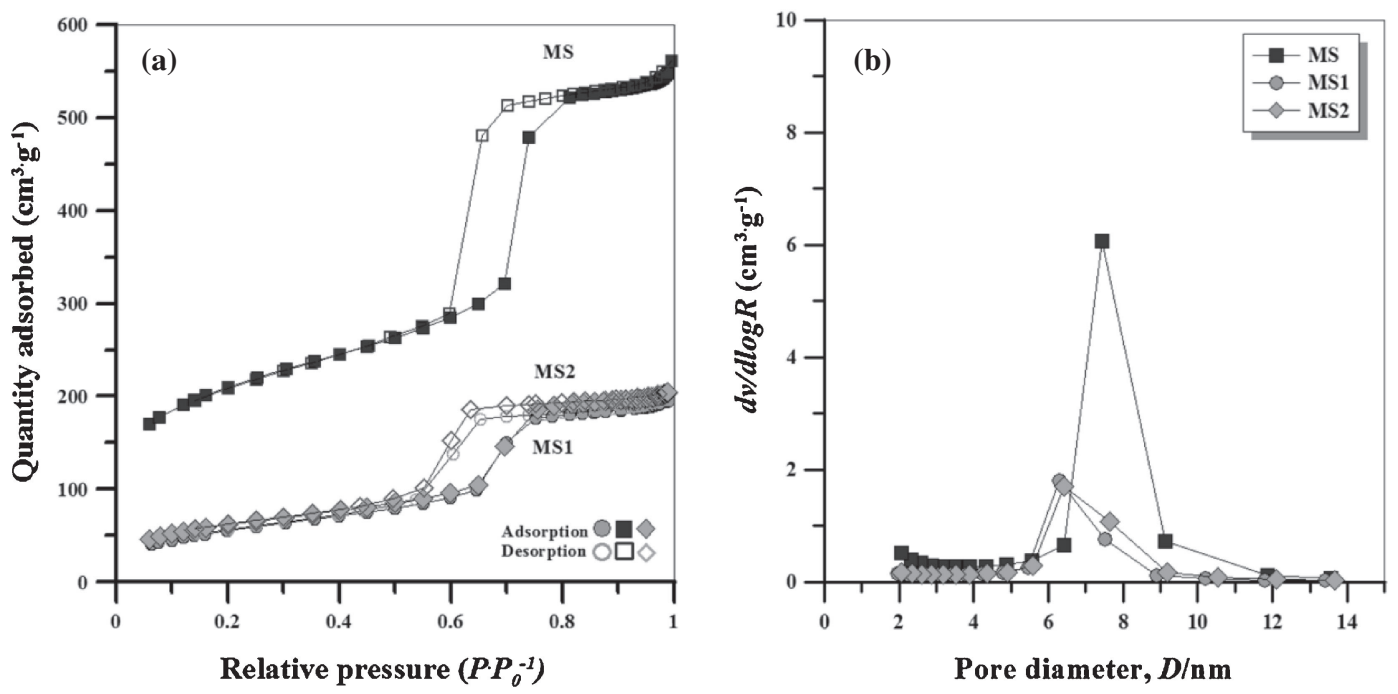

Fig. 2 (a) Nitrogen adsorption-desorption isotherms and (b) pore size distributions of MS, MS1 and MS2, respectively.
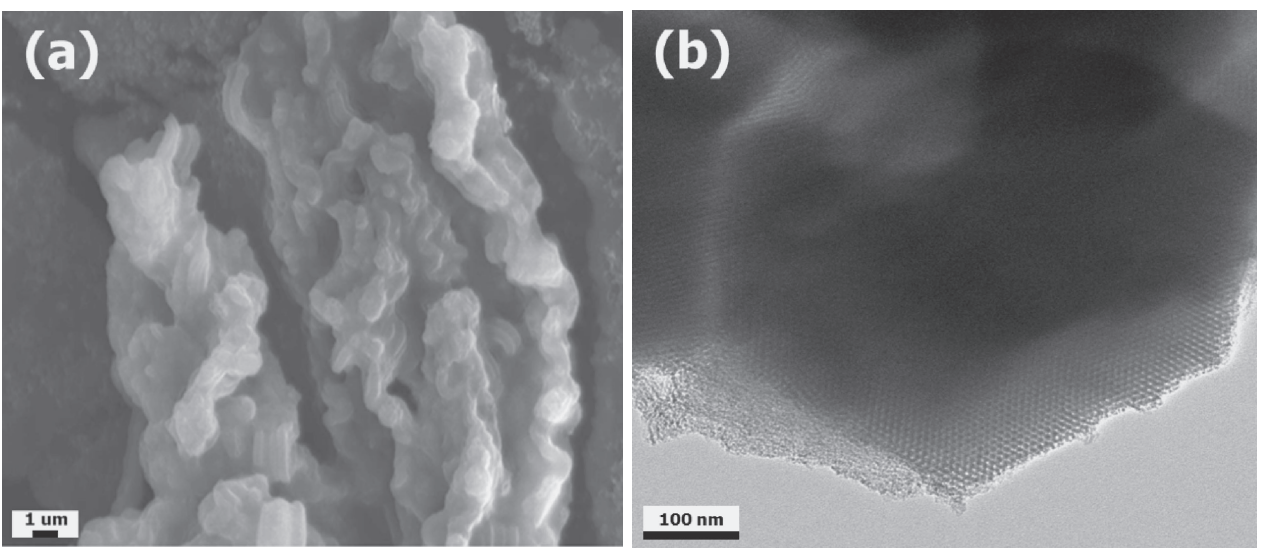

Fig. 3 (a) SEM image and (b) TEM image of the MS.

MS1 and MS2 exhibited new peaks related to the organic functionality: (1) the vibrational modes of the amino groups $\mathrm{NH}_{2}$ at $3370 \mathrm{~cm}^{-1}$ and $\mathrm{NH}_{3}{ }^{+}$at $1620 \mathrm{~cm}^{-1}$, (2) the stretching and bending modes of the $\mathrm{CH}_{2}$ groups at 2930 and $1385 \mathrm{~cm}^{-1} \cdot{ }^{10,12,29-31)}$ These groups resulted from the surface functionalization agents which contain $\mathrm{N}, \mathrm{H}$, and $\mathrm{C}$. The Si$\mathrm{OH}$ peak intensity in MS1 and MS2 was reduced because of the substitution of the $\mathrm{Si}-\mathrm{OH}$ groups by the amino groups. And the element analysis of the adsorbents showed that they contain $3.78 \%(2.70 \mathrm{mmol} / \mathrm{g})$ and $3.31 \%(2.36 \mathrm{mmol} / \mathrm{g})$ in MS1 and MS2, respectively. The data obtained from elemental analysis confirm the success of the functionalization.

Figure 2 shows the nitrogen adsorption-desorption isotherms and pore size distributions from the adsorption branch of the different adsorbents, respectively. The physical and chemical properties obtained from the experimental isotherms are shown in Table 1 . The specific surface, pore size, and pore volume of MS1 became much smaller than MS. This observation confirms that there are amounts of the organic chain of the mesoporous silica surface due to the functionalization. Each sample shows the type IV isotherm according to the international union of pure and applied chemistry (IUPAC) classification with H1 hysteresis loops representing the mesoporous materials. ${ }^{32)}$ After the function-
Table 1 Physical and chemical properties of the MS, MS1 and MS2, respectively.

\begin{tabular}{ccccc}
\hline Materials & $\begin{array}{c}\text { Surface area } \\
, A / \mathrm{m}^{2} \cdot \mathrm{g}^{-1 *_{1}}\end{array}$ & $\begin{array}{c}\text { Pore diameter } \\
, D / \mathrm{nm}^{* 2}\end{array}$ & $\begin{array}{c}\text { Pore volume } \\
, V / \mathrm{cm}^{3} \cdot \mathrm{g}^{-*_{3}}\end{array}$ & $\begin{array}{c}\mathrm{N} \text { contents } \\
/ \%, \\
\mathrm{mmol} \cdot \mathrm{g}^{-1 *_{4}}\end{array}$ \\
\hline MS & 747.5 & 6.11 & 0.79 & - \\
MS1 & 206.1 & 5.60 & 0.31 & $3.78,2.70$ \\
MS2 & 226.5 & 5.80 & 0.33 & $3.31,2.36$ \\
\hline
\end{tabular}

${ }^{*}$ Calculated by BET method

${ }^{*}$ Calculated by BJH method in the adsorption branch

${ }^{*}$ Calculated by BJH method in the adsorption branch

${ }^{*}$ Measured by element analyzer

alization, the pore structure of the adsorbents was maintained because the shape of the isotherms and the hysteresis loops are similar to SBA15.

Figure 3 shows the SEM and TEM image of the mesoporous silica MS. They exhibited the cylindrical and hexagonal pore structures of typical SBA15.

\subsection{Adsorption of $\mathrm{Co}$ (II) and $\mathrm{Mn}$ (II) in a single component system}

The effects of $\mathrm{pH}$ on adsorption of $\mathrm{Co}(\mathrm{II})$ and $\mathrm{Mn}$ (II) onto the functionalized SBA15 are presented in Fig. 4. In this 
figure, the adsorption capacity was attained at $\mathrm{pH}$ ranging from 2 to 3 , closed to the isoelectric point of the mesoporous silica. This observation confirms that the decrease in the positive surface charge have been occur lower electrostatic repulsions between the surface of the adsorbent and metal ions.

Table 2 shows that the batch tests with the Co(II) and $\mathrm{Mn}(\mathrm{II})$ solutions were used to compare the adsorption capacity of the three different adsorbents MS, MS1, and MS2. In this table, the adsorption capacity of Co(II) on MS1 was significantly enhanced in comparison to the other materials. The adsorption capacity of Mn(II) on MS2 was

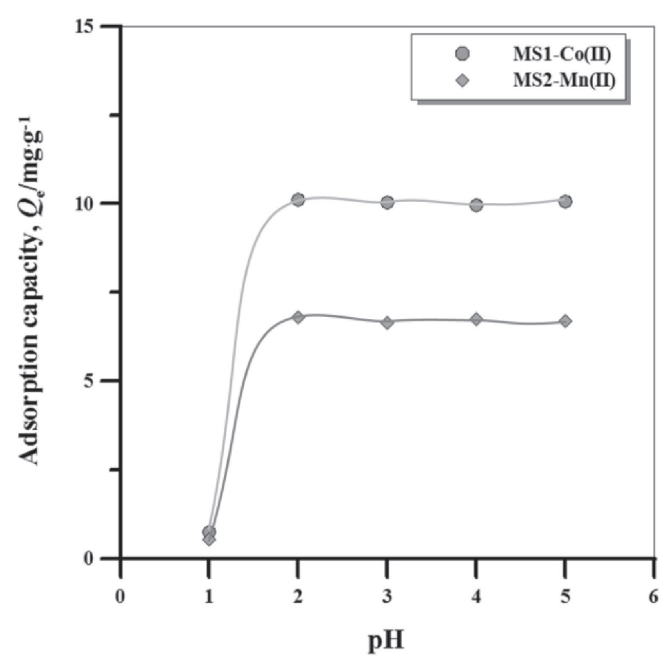

Fig. 4 Effects of $\mathrm{pH}$ on adsorption of $\mathrm{Co}$ (II) onto MS1 and Mn(II) onto MS2, respectively.

Table 2 Adsorption capacity of mesoporous silicas MS, MS1 and MS2 for $\mathrm{Co}(\mathrm{II})$ and $\mathrm{Mn}(\mathrm{II})$ in single component system at $25^{\circ} \mathrm{C}$ and $\mathrm{pH} 2.0$.

\begin{tabular}{ccc}
\hline \multirow{2}{*}{ Materials } & \multicolumn{2}{c}{ Adsorption capacity, $Q_{\mathrm{e}} / \mathrm{mg} \cdot \mathrm{g}^{-1}$} \\
\cline { 2 - 3 } & $\mathrm{Co}(\mathrm{II})$ & $\mathrm{Mn}(\mathrm{II})$ \\
\hline MS & 0.91 & 0.72 \\
MS1 & 10.12 & 1.02 \\
MS2 & 1.73 & 6.8 \\
\hline
\end{tabular}

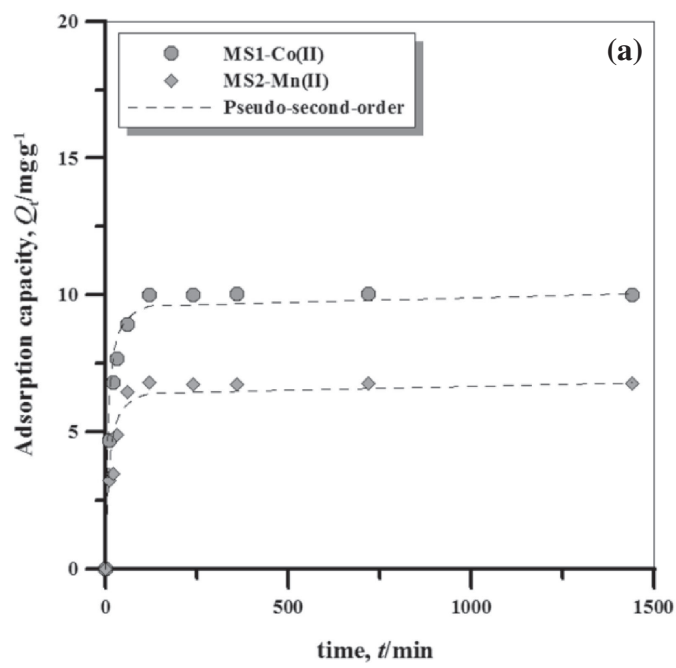

significantly enhanced in comparison to other materials. The differences in the adsorption capacities of MS, MS1, and MS2 are due to the presence of an amine group on the surface of the mesoporous silica. Specifically, MS1 and MS2 exhibit larger adsorption capacities than unmodified MS as the amine group has a high affinity toward metal ion. According to recent research, the metal adsorption efficiency of the surface-modified mesoporous silica increased due to the presence of the functional groups. ${ }^{19,31)}$

\subsection{Adsorption kinetics}

Figure 5(a) shows that the adsorption of $\mathrm{Co}(\mathrm{II})$ and $\mathrm{Mn}(\mathrm{II})$ is a time dependence process. The adsorption process was rapid in the first $30 \mathrm{~min}$. At the initial adsorption stage, the adsorbent surface contained a lot of available active sites for metal binding, and fast adsorption took place. After this adsorption slowed down due to the decrease of the concentration of metals in the solutions phase as well as the possible location of active sites in the positions that were not easily available (e.g. inside the pores). The adsorption kinetic study is helpful to understand the mechanism of the adsorption reactions. The Pseudo-second order kinetic model is based on the assumption that the rate-limiting step may be chemisorption. This chemical adsorption involves valency forces through the sharing or exchange of electrons between the adsorbent and adsorbate, which is suitable for adsorption at a low initial concentration. Figure 5(b) shows that the results of the two adsorbents MS1 and MS2 fit well with the Pseudo-second-order eq. (3) $\left(R^{2}>0.99\right)$. This observation confirms that the $\mathrm{Co}(\mathrm{II})$ and $\mathrm{Mn}(\mathrm{II})$ adsorption onto the adsorbents involves chemical adsorption through the formation of the metal complex with the amine group of the mesoporous silica surface.

\subsection{Adsorption isotherms}

The adsorption isotherms represent the adsorption capacity of the adsorbent as a function of the adsorbate concentration in the solution. A Langmuir isotherms model was chosen for the equilibrium calculations since it is commonly used in the description of liquid-solid systems. The Langmuir isotherm

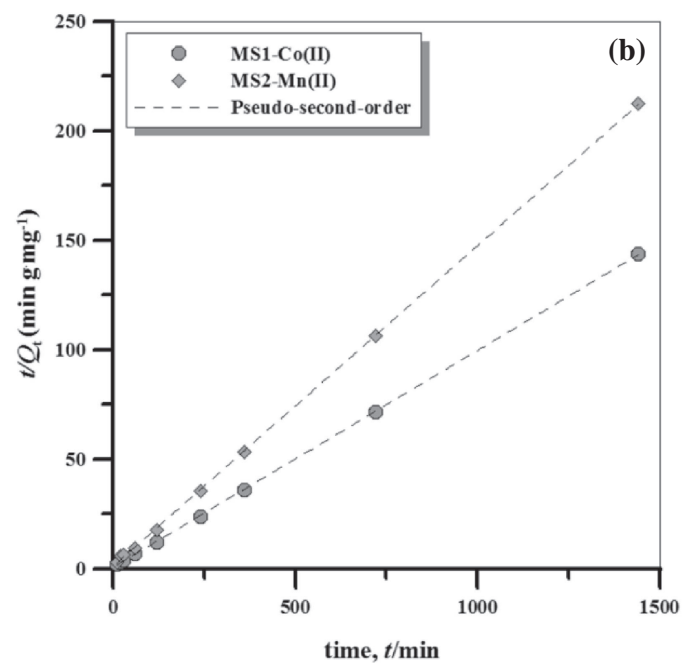

Fig. 5 (a) Effect of time and (b) Pseudo-second-order adsorption kinetics of the adsorption for Co(II) and Mn(II) by the MS1 and MS2 at $25^{\circ} \mathrm{C}$ and $\mathrm{pH} 2.0$. 

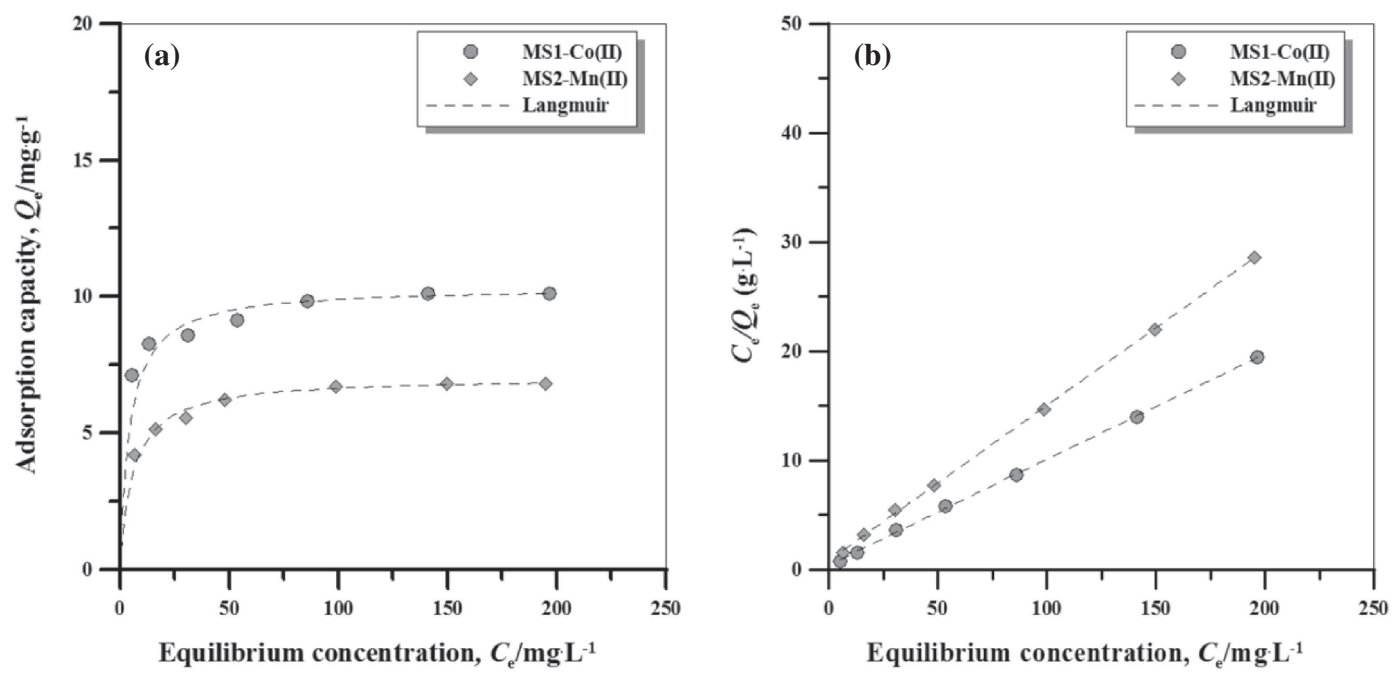

Fig. 6 (a) Non-linear Langmuir adsorption isotherms and (b) linear Langmuir isotherms of the adsorption for Co(II) and Mn(II) by MS1 and $\mathrm{MS} 2$ at $25^{\circ} \mathrm{C}$ and $\mathrm{pH} 2.0$.

assumes that adsorption occurs at specific homogeneous sites within the adsorbent without any interaction between the adsorbed substances and the monolayer adsorption. The adsorption data of $\mathrm{Co}(\mathrm{II})$ and $\mathrm{Mn}(\mathrm{II})$ on MS1 and MS2 as a function of the initial concentration of the metal ion at $\mathrm{pH} 2.0$ is shown in Fig. 6(a). In the figure, the adsorption curves indicate that the adsorption capacity of MS1 and MS2 for $\mathrm{Co}$ (II) and $\mathrm{Mn}$ (II) increases as the initial concentration of the metal ion increases until reaching the plateau. Figure 6(b) shows that the equilibrium data of the adsorption fit well with the Langmuir adsorption isotherm eq. (5) $\left(R^{2}>0.99\right)$.

\subsection{Adsorption of $\mathrm{Co}$ (II) and $\mathrm{Mn}$ (II) in binary compo- nents system}

Table 3 shows the adsorption capacity of the adsorbents for $\mathrm{Co}(\mathrm{II})$ and $\mathrm{Mn}(\mathrm{II})$ in a binary system. In the binary components system, the adsorbents achieved over $95 \%$ of the adsorption capacity in comparison with the usage of a single component system and more selectivity of $\mathrm{Co}(\mathrm{II})$ and $\mathrm{Mn}(\mathrm{II})$ in each metal ion (Table 3 ).

\subsection{Regeneration efficiency}

Regeneration of a spent adsorbent is necessary to restore its original adsorption capacity. This enables valuable metals to be recovered from aqueous solutions that contain metal ions. In this study, desorption of MS1 and MS2 was almost complete for $\mathrm{Co}(\mathrm{II})$ and $\mathrm{Mn}(\mathrm{II})$ using $2 \mathrm{M} \mathrm{HNO} 3$ solution. These results indicate the suitability of $2 \mathrm{M} \mathrm{HNO}_{3}$ solution as a desorption agent for both adsorbents. Then, regeneration efficiency of over $90 \%$ for the adsorbents after 5 cycles was achieved. The adsorption efficiency was slightly reduced in the subsequent cycles.

\section{Conclusions}

Functionalized mesoporous materials with amino functional groups were synthesized to achieve $\mathrm{Co}(\mathrm{II})$ and $\mathrm{Mn}(\mathrm{II})$ adsorbents from aqueous solution using surface functionalization agents such as EDTA and DMAC. The adsorption capacity of the metal ions on the MS1 and MS2 was
Table 3 Adsorption capacity of functionalized mesoporous silicas MS1 and MS2 for $\mathrm{Co}(\mathrm{II})$ and $\mathrm{Mn}(\mathrm{II})$ in binary component system at $25^{\circ} \mathrm{C}$ and $\mathrm{pH} 2.0$.

\begin{tabular}{ccc}
\hline \multirow{2}{*}{ Materials } & \multicolumn{2}{c}{ Adsorption capacity, $Q_{\mathrm{e}} / \mathrm{mg} \cdot \mathrm{g}^{-1}$} \\
\cline { 2 - 3 } & $\mathrm{Co}(\mathrm{II})$ & $\mathrm{Mn}(\mathrm{II})$ \\
\hline MS & 0.32 & 0.28 \\
MS1 & 9.73 & 0.21 \\
MS2 & 0.15 & 6.51 \\
\hline
\end{tabular}

significantly higher than MS. The adsorption results of the adsorbents for $\mathrm{Co}$ (II) and $\mathrm{Mn}$ (II) fit well with the Pseudosecond order kinetic model and the Langmuir adsorption isotherm model. Moreover, the adsorbents could be regenerated for subsequent use with regeneration efficiencies of over $90 \%$ after 5 cycles and more selectivity in the binary components system. These results are relatively promising, as the used adsorbents could be regenerated and reused for subsequent use, thus improving their cost-effectiveness and reducing the operational cost of metal recovery applications.

\section{REFERENCES}

1) L. Li, J. Lu, Y. Ren, X. X. Zhang, R. J. Chen, F. Wu and K. Amine: J. Power Sources 218 (2012) 21-27.

2) S. H. Joo, J. Kang, K. Woong and S. M. Shin: Mater. Trans. 54 (2013) 844-849.

3) L. Li, J. Ge, F. Wu, R. Chen, S. Chen and B. Wu: J. Hazard. Mater. 176 (2010) 288-293.

4) M. Asari and S.-i. Sakai: Resour. Conserv. Recy. 81 (2013) 52-59.

5) L. Li, J. Ge, R. Chen, F. Wu, S. Chen and X. Zhang: Waste Manage. 30 (2010) 2615-2621.

6) L. Chen, X. Tang, Y. Zhang, L. Li, Z. Zeng and Y. Zhang: Hydrometallurgy 108 (2011) 80-86.

7) J. Nan, D. Han, M. Yang, M. Cui and X. Hou: Hydrometallurgy 84 (2006) 75-80.

8) M. S. Gasser and M. I. Aly: Int. J. Miner. Process. 121 (2013) 31-38.

9) H. Zheng, D. Hu, L. Zhang, C. a. Ma and T. Rufford: Miner. Eng. 35 (2012) 20-26.

10) M. Anbia and M. Lashgari: Chem. Eng. J. 150 (2009) 555-560.

11) E. Repo, J. K. Warchol, T. A. Kurniawan and M. E. T. Sillanpää: Chem. 
Eng. J. 161 (2010) 73-82.

12) L. Yang, Y. Li, X. Jin, Z. Ye, X. Ma, L. Wang and Y. Liu: Chem. Eng. J. 168 (2011) 115-124.

13) R. Marković, J. Stevanović, Z. Stevanović, M. Bugarin, D Nedeljković, A. Grujić and J. Stajić-Trošić: Mater. Trans. 52 (2011) 1849-1852.

14) E. Repo, T. A. Kurniawan, J. K. Warchol and M. E. T. Sillanpää: J. Hazard. Mater. 171 (2009) 1071-1080.

15) A. M. Donia, A. A. Atia, E. M. M. Moussa, A. M. El-Sherif and M. O. Abd El-Magied: Hydrometallurgy 95 (2009) 183-189.

16) A. M. Donia, A. A. Atia, A. M. Daher, O. A. Desouky and E. A Elshehy: Int. J. Miner. Process. 101 (2011) 81-88.

17) H. Nagata, M. Takimura, Y. Yamasaki and A. Nakahira: Mater. Trans. 47 (2006) 2103-2105.

18) F. Hoffmann, M. Cornelius, J. Morell and M. Fröba: Angew. Chem. Int Edit. 45 (2006) 3216-3251.

19) M. Mureseanu, A. Reiss, I. Stefanescu, E. David, V. Parvulescu, G. Renard and V. Hulea: Chemosphere 73 (2008) 1499-1504.

20) D. Zhao, Q. Huo, J. Feng, B. F. Chmelka and G. D. Stucky: J. Am. Chem. Soc. 120 (1998) 6024-6036.

21) Y. S. Han, H. J. Kim, J. K. Park, S. H. Lee and J. Y. Kim: Int. J. Hydrogen Energ. 37 (2012) 14240-14247.
22) J. H. Park, J. K. Park and H. Y. Shin: Mater. Lett. 61 (2007) 156-159.

23) L. Bois, A. Bonhommé, A. Ribes, B. Pais, G. Raffin and F. Tessier: Colloid. Surf. A 221 (2003) 221-230.

24) T. Yokoi, H. Yoshitake, T. Yamada, Y. Kubota and T. Tatsumi: J. Mater. Chem. 16 (2006) 1125-1135.

25) C. Liu and R. Bai: J. Colloid Interf. Sci. 350 (2010) 282-289.

26) R. Qu, M. Wang, R. Song, C. Sun, Y. Zhang, X. Sun, C. Ji, C. Wang and P. Yin: J. Chem. Eng. Data 56 (2011) 1982-1990.

27) K. Z. Elwakeel, G. O. El-Sayed and R. S. Darweesh: Int. J. Miner. Process. 120 (2013) 26-34.

28) G. Li, Z. Zhao, J. Liu and G. Jiang: J. Hazard. Mater. 192 (2011) $277-$ 283.

29) S. W. Lai, H. L. Lin, T. L. Yu, L. P. Lee and B. J. Weng: Int. J. Hydrogen Energ. 37 (2012) 14393-14404.

30) P. Iliade, I. Miletto, S. Coluccia and G. Berlier: Res. Chem. Intermediat. 38 (2012) 785-794.

31) A. Heidari, H. Younesi and Z. Mehraban: Chem. Eng. J. 153 (2009) 70-79.

32) K. S. W. Sing, D. H. Evereit, R. A. W. Haul, L. Moscou, R. A. Piertti, J. Rouquerol and T. Siemieniewska: Pure Appl. Chem. 57 (1985) 603619. 